American Journal of Applied Sciences 7 (11): 1458-1463, 2010

ISSN 1546-9239

(C) 2010 Science Publications

\title{
Low Cost Interactive Electronic Whiteboard Using Nintendo Wii Remote
}

\author{
${ }^{1}$ Dalbir Singh, ${ }^{2}$ Ridha Omar and ${ }^{2}$ Azfar Anuar \\ ${ }^{1}$ Center of Computer Science, Faculty of Information Science and Technology, \\ National University of Malaysia, 43600 Bangi, Selangor, Malaysia \\ ${ }^{2}$ Department of Graphic and Multimedia, College of Information Technology, \\ University Tenaga Nasional, Km 7, Jalan Kajang-Puchong, 43009 Kajang, Selangor, Malaysia
}

\begin{abstract}
Problem statement: The application of interactive whiteboard offers extensive benefits in the learning and teaching process for classroom environment. The high cost associated with commercial interactive whiteboard may hinder its application in primary or secondary school, especially in developing countries. Thus, this study describes the methods used to create a low cost interactive and viable electronic whiteboard by using the capabilities of the Nintendo Wiimotes. It also looks at the possibility of whether this much cheaper technology can be fully utilized to create better tools for in-class learning. Approach: Several technical aspects of the Wii Remote are examined, how this technology can be used on a low cost interactive whiteboard and how the system can be connected to your computer and LCD projector/screen. Result: This system has a stand-alone architecture, consists of a PC. The input client was responsible for getting the input data and connecting the Wii Remotes using a Bluetooth connection. The PC handles the software engine and display module. The user sends the IR source light to Wiimote by pressing the IR Pen's switch button and then the Wiimote sends data to the PC via a Bluetooth connection. Conclusion/Recommendations: The genre of the system makes it more suitable in learning environments such as schools or universities. The main target groups of the system are lecturers, teachers or students (during presentation or in class exercise). Therefore, it was necessary to simplify the software design and control mechanism in order to support these main target groups.
\end{abstract}

Key words: Overhead Projectors (OHPs), Light-Emitting Diode (LED), calibration process, Bluetooth connection, Field Of View (FOV), stand-alone architecture, nintendo wii remote, computer projection systems, interaction design

\section{INTRODUCTION}

Overhead Projectors (OHPs) were once a common fixture in most classrooms and business conference rooms, but today they are slowly being replaced by Document Cameras, large computer monitors, dedicated computer projection systems and interactive whiteboards. Such systems allow making animations, interactive presentations with movement and videos, typically using software like Microsoft PowerPoint or other authoring tools. The primary reason for this gradual replacement is the deeply ingrained use of computing technology in modern society and the inability of OHPs to easily support the features that modern users' demand (Lanir et al., 2010).

However, critics feel that there are some downsides, these technologies are more prone to failure and have a much steeper learning curve for users as compared to a standard OHP (Savoy et al., 2009). While a computer projection system eliminates the need to create hard copy transparencies (which can be quite expensive, particularly if printed in colour) of the presentation, many presenters do make both version (softcopy and hardcopy versions) in case of a computer hardware failure. The overhead projector also allows a more direct interaction through live writing on the transparency. Therefore, in this study, a novel strategy is presented that outlines the concept of interactivity between the presenter and the audiences for modern projector/large monitor based presentation with the use of Nintendo Wii Remote (Peek and Fernandez, 2008). It utilizes the interactivity attributes of the overhead projector and whiteboard (Lee, 2008; Jayakumar and Gopinath, 2007). It focuses on low cost solution for existing (projector/large monitor) classroom based teaching and learning environment.

Corresponding Author: Dalbir Singh, Faculty of Information Science and Technology, National University of Malaysia, 43600 Bangi, Selangor, Malaysia 
System architectural: This system has a stand-alone architecture, consists of a Personal Computer (PC), Infrared (IR)/Light-Emitting Diode (LED) Pen and two Wiimotes (Mantilla-Gomez and Palacio-Gonzalez, 2009). It is illustrated in Fig. 1. The PC handles the software engine and display. It is also responsible for getting the input data and connecting the Wii Remotes using a Bluetooth connection. The user sends the IR source light to Wiimote by pressing the IR Pen switch button and then the Wiimote sends data to the PC via a Bluetooth connection.

Hardware design: Below are the hardware setup descriptions of the proposed Low Cost Interactive Whiteboard using Wii Remote:

Screen: The minimum screen size is 20 square inch and it can go up to a size of a cinema screen, depending on the user's height and flexibility. The maximum distance between Wiimote and the screen depends on the IR source. (The IR source should be visible to the Wiimote). Refer Fig. 2 and 3 for more details.

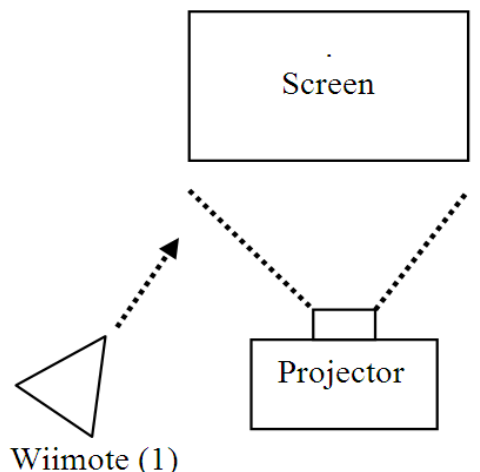

Wiimote (1)

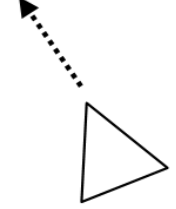

Wiimote (2)

Fig. 1: Overall system architecture

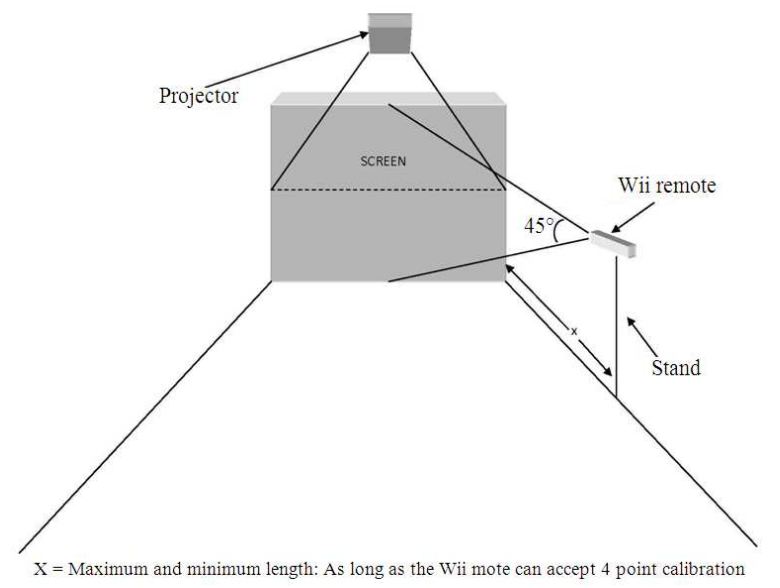

Fig. 2: Wii remote projection (1)
Wii remote: The IR sources must be within the Field Of View (FOV) of the Wii remote IR camera. It consists of 3 axis $(x, y, z)$ as described in Fig. 4. The arrangement of the Wii remote is based on the surrounding environment. Wii Remotes should be able to "see" clearly (without any obstructions) the four IR points of calibration in order to be used as a capture device. The Wii remote infrared camera is not just any typical infrared camera. The actual infrared tracking is accomplished using hardware within the Wii remote.

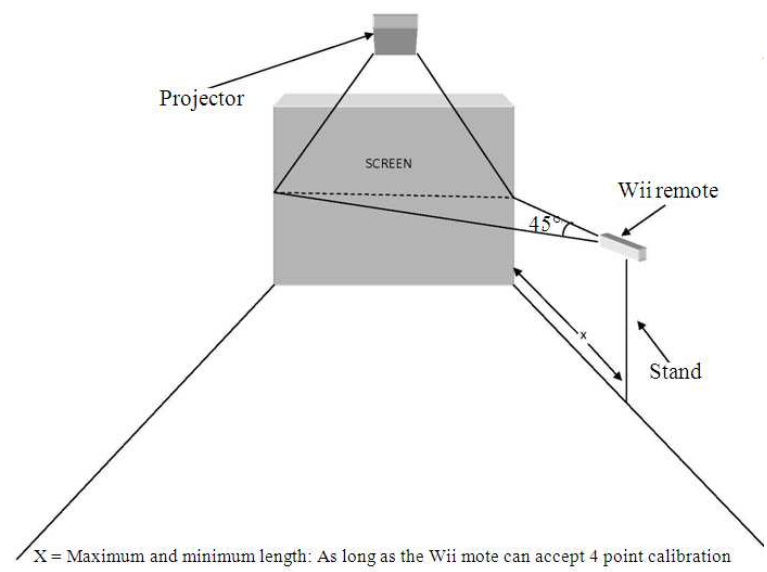

Fig. 3: Wii remote projection (2)

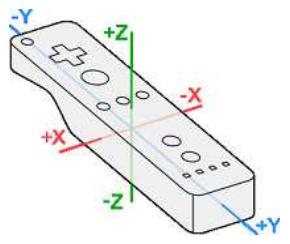

Fig. 4: Wii Remote 3D axis (x, y, z)

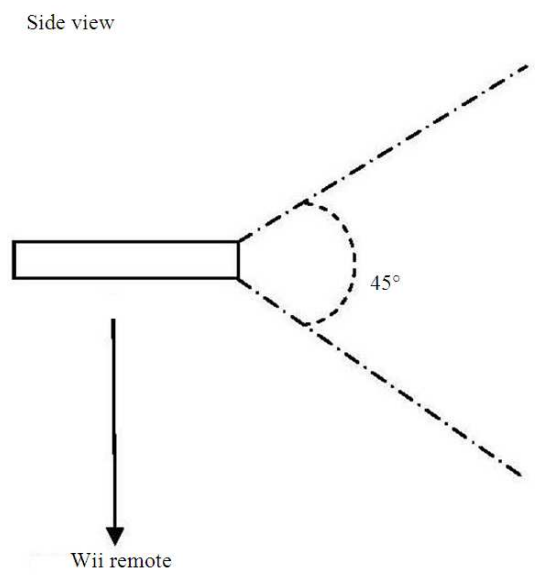

Fig. 5: Wii remote side view projection 


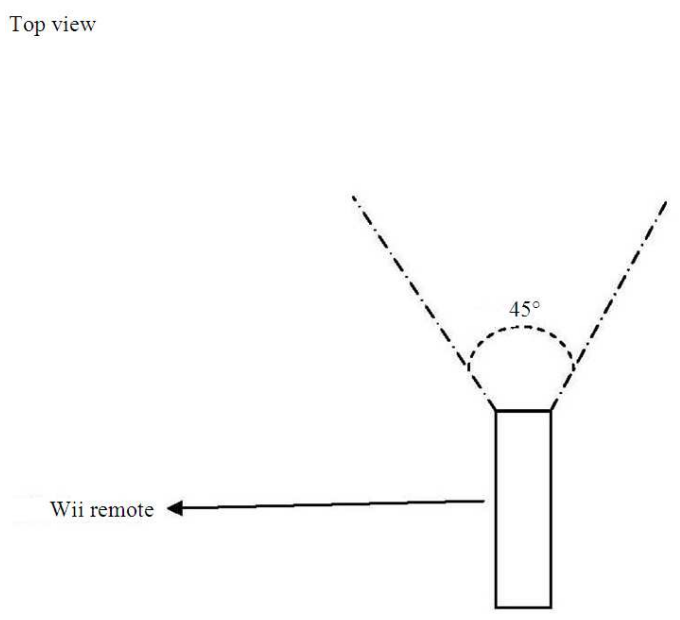

Fig. 6: Wii remote top view projection
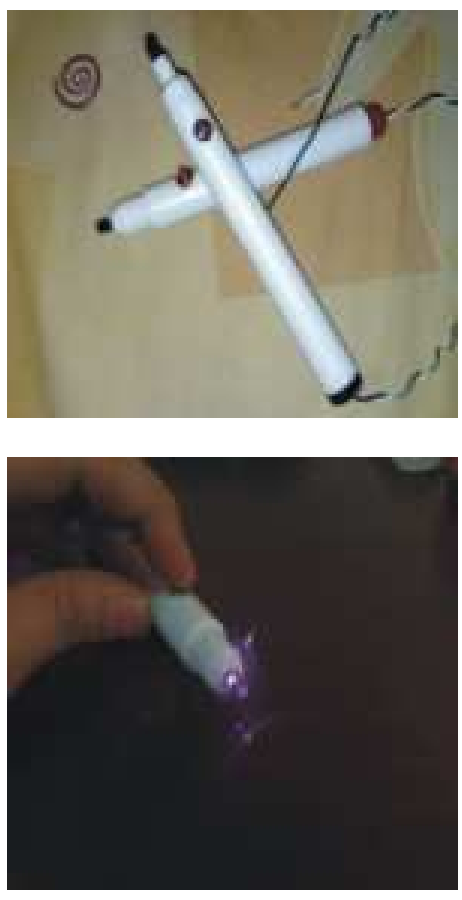

Fig. 7: IR LED Pen

It then sends the position data via Bluetooth to a PC. (No processing resources are wasted with tracking code). It has an infrared camera in it which tracks the position of up to 4 infrared light sources. The limitation of this camera is that it only has a $45^{\circ}$ angle opening. Refer Fig. 5 and 6. Therefore objects placed at the side of the Wiimote camera are "unseen". In this project, the system needs to be placed indoor to avoid direct sunlight and also in a non reflective environment (avoiding any shiny surfaces near the setup).

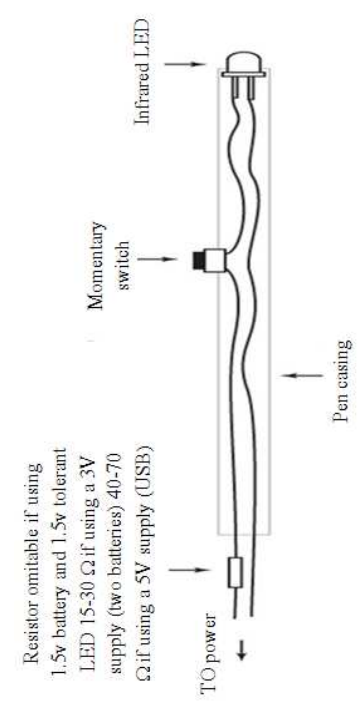

Fig. 8: IR pen architecture

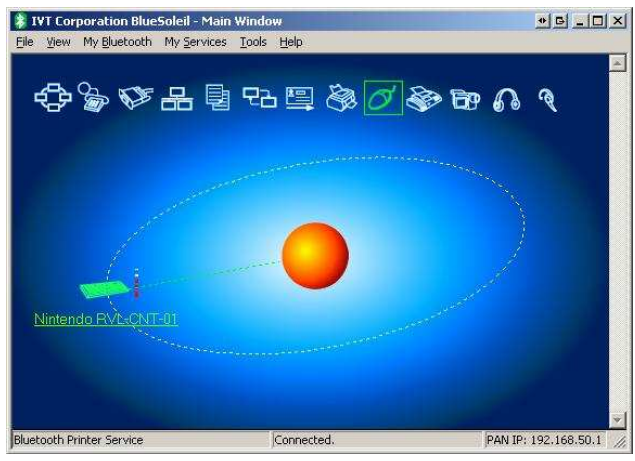

Fig. 9: A successful Wii Remote pairing using Bluesoleil

IR Sources/IR pen: The IR Pen is powered by a $1.5 \mathrm{~V}$ battery, when the battery is running low, the IR source will not be strong or stable enough. Its layout and architecture is illustrated in Fig. 7 and 8. This will eventually make the IR points not clearly visible to the Wii Remote. This can be resolved by replacing the battery with a power source that has a stronger capacity voltage, but this requires a resistor to protect the IR LED from being burned.

Software interaction design: To test the concept of the low cost interactive whiteboard using Wii Remote, a software prototype is developed. It is paired using Bluesoleil (Refer Fig. 9). The user will control the system using their IR pen. There are three interaction methods utilised when using the IR pen:

\section{- Pointing}


- Pressing and releasing the switch button (click/double click)

- Pressing and holding the switch button (dragging), which will be explored and used to control the system

Interaction design using Wii remote: Another purpose of this project is to evaluate the three common mouse-based interaction methods by using the IR Pen. These interaction methods are:

- Point. The IR pen is used as a pointing device. The user points it to the screen and when the switch button is pressed and the cursor will appear

- Press/Click. The user holds the IR pen and pressing the switch button (hold, single push, double push)

\section{METERIALS AND METHODS}

Hardware: A desktop computer is used. The machine must have sufficient processing power to get input from Wii Remote and to process the input data. The most important hardware for the machine is the Bluetooth capable hardware. For this purpose, a USB Bluetooth dongle or a laptop with built-in Bluetooth hardware is used.

Software: C\# and .Net technology from Microsoft are used to develop the prototype application. As for the IDE, Microsoft Visual Studio 2008 Express Edition is used (Randolph and Gardner, 2008). It provides an integrated application for editing the source codes, compiling and debugging processes. It can be downloaded for free and it is a highly recommended platform to develop application utilizing $\mathrm{CH}$ and .Net technology. The software development toolkit -SDK used for the development is Peek and Fernandez (2008).

Calibration features: There are several steps which must be implemented to calibrate the wii remotes and their receiver. Firstly, the system must be able to connect and detect the pair of Wii-Motes. Up to four Wii Remotes are supported by the machine but not in this beta version. Once the Wii Remotes are connected, we can calibrate the windows by using an IR Pen. The connection status and settings are shown in Fig. 10. The calibration is done by pointing the IR pen to the target crosshair (4 points calibration, each done at the angle of the projected screen or monitor) and by pressing momentary and then releasing the switch button. The calibration process is completed when the windows desktop appears. Once this process is successful, we can then use the IR pen just like ordinary WIMP-based mouse functionalities. The series of calibration steps are shown in Fig. 11-14.

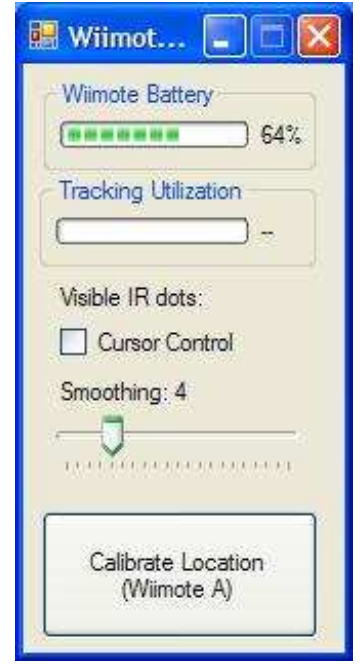

Fig. 10: Wii remote connection

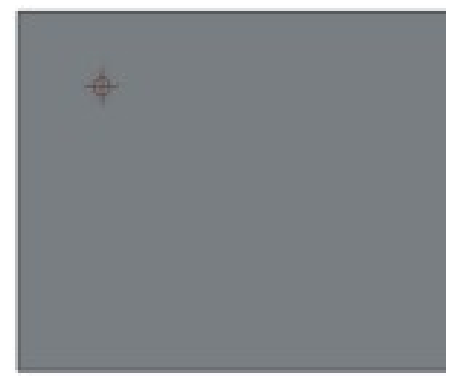

Fig. 11: First point calibration

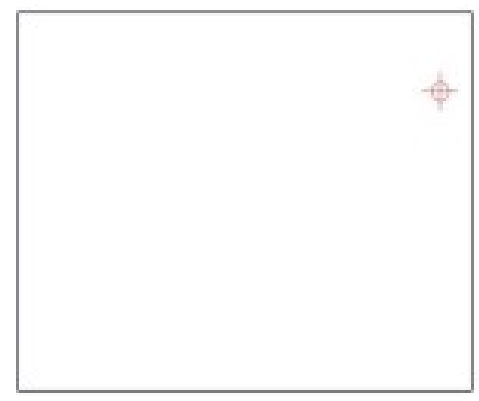

Fig. 12: Second point calibration

Testing and evaluation: Below are the summarized outcomes of the testing and evaluation process:

- The Wiimote has the ability to compute four points of calibration (x,y-axis on 2-plane). Thus, this enables the board to be used to the maximum capabilities with regards to the maximum angle of $45^{\circ}$ of the Wiimote and its distance to the board 
Am. J. Applied Sci., 7 (11): 1458-1463, 2010
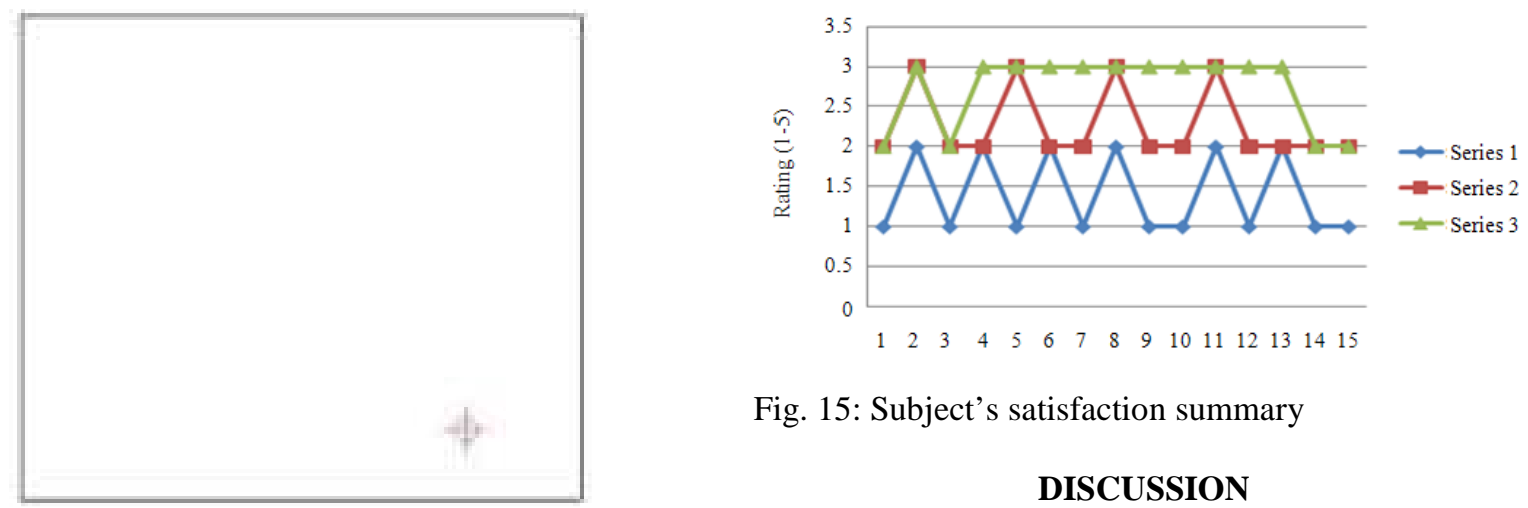

Fig. 15: Subject's satisfaction summary

\section{DISCUSSION}

Fig. 13: Third point calibration

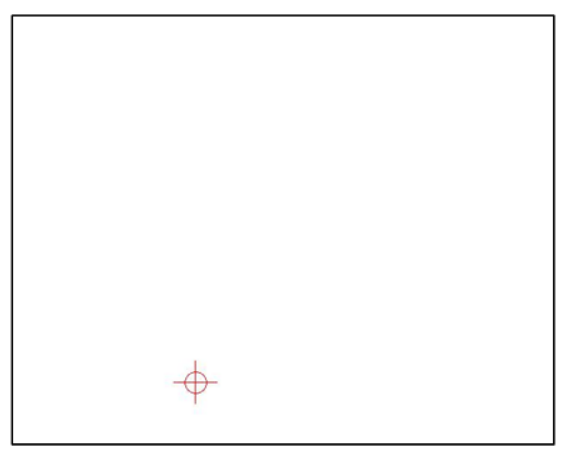

The subjects, specially the teachers were satisfied with the overall functionality. The prototype eases and aids their teaching process. The satisfaction level increases after each series (learnability level). Therefore the hypothesis of this project is proven. On the other side, the teachers complain and express their dissatisfaction about the initial calibration process. Based on the observation, the calibration process took a longer time than expected. Thus, for future recommendation, further steps would be carried out to improve its interface and addition of self- calibration features.

\section{CONCLUSION}

Fig. 14: Fourth point calibration

- The system is feasible for usage in a small classroom where there is little or no interference is expected from other light sources

- In terms of the interaction methods, the drag-anddrop feature was rather unstable. However, both the single click and double clicks operations were very much stable and produce excellent results

\section{RESULTS}

In the testing phase, the prototype was developed and tested. The test subject comprises 15 school teachers. The test subjects were given training on how to calibrate and apply it in their classroom's teaching environment. There were 3 series of experiments that caters of 2 different teaching materials for different group of students. Questionnaires (teachers and students) were distributed and direct observation was conducted (video recording during the teaching process) to measure the satisfaction and learnability level. Figure 15 summaries the satisfaction and learnability level among the subjects.

Based on the experiment results, a low cost interactive whiteboard coupled with the capabilities of the Wiimote is feasible for development and provides a practical solution in terms of usage in a classroom setting. The Low Cost Interactive Whiteboard software can be utilised using the two interaction methods which can be done using an IR Pen: pointing, pressing (only single and double click functions and right click function). As for future enhancements, the prototype system developed will have better graphical user interface designs and auto-calibration features (Wingrave et al., 2010).

\section{ACKNOWLEDGEMENT}

The researchers would like to thank the Malaysian Ministry of Science, Technology and Environment (MOSTE) for the research project's funding.

\section{REFERENCES}

Lanir, J., K.S. Booth and K. Hawkey, 2010. The benefits of more electronic screen space on students' retention of material in classroom lectures. Comput. Educ., 55: 892-903. DOI: 10.1016/j.compedu.2010.03.020 
Lee, J.C., 2008. Hacking the Nintendo Wii remote. IEEE Pervasive Comput., 7: 39-45. DOI: 10.1109/MPRV.2008.53

Mantilla-Gomez, F. and A. Palacio-Gonzalez, 2009. An accessibility framework based on Wiimote. Proceeding of the 9th WSEAS International Conference on Applied Informatics and Communications, World Scientific and Engineering Academy and Society (WSEAS) Stevens Point, Aug. 20-22, Wisconsin, USA., pp: 363-365. ISBN: 978-960-474-107-6

Peek, B. and D. Fernandez, 2008. Coding4Fun: 10. NET Programming Projects for Wiimote, YouTube, World of Warcraft and More. 1st Edn., O'Reilly Media, Inc., ISBN: 0596520743 9780596520748, pp: 510.
Randolph, N. and D. Gardner, 2008. Professional Visual Studio. 1st Edn., Wrox Press Ltd, ISBN: 04702298889780470229880 , pp: 1032.

Savoy, A., R.W. Proctor and G. Salvendy, 2009. Information retention from PowerPoint ${ }^{\mathrm{TM}}$ and traditional lectures. Comput. Educ., 52: 858-867. DOI: 10.1016/j.compedu.2008.12.005

Wingrave, C.A., B. Williamson, P.D. Varcholik, J.R.A. Miller and E. Charbonneau, 2010. The Wiimote and Beyond: Spatially Convenient Devices for 3D User Interfaces. IEEE Comput. Graphics Appl., 30: 71-85. DOI: 10.1109/MCG.2009.109

Jayakumar, G. and G. Gopinath, 2007. Ad hoc mobile wireless networks routing protocols-a review. J. Comp. Sci., 3: 574-582. DOI: 10.3844/jcssp.2007.574.582 